\title{
Manpower Discipline Based on Knowledge Skills: The Case of a Consulting Company in Iranian Commercial Marine...
}

Article in SSRN Electronic Journal · January 2012

DOI: $10.2139 /$ ssrn.2188298

CITATIONS

0

3 authors:

Peyman Akhavan

Malek Ashtar University of Technology

127 PUBLICATIONS 833 CITATIONS

SEE PROFILE

\section{Amir Pezeshkan}

University of Baltimore

16 PUBLICATIONS 69 CITATIONS

SEE PROFILE

READS

149

\section{Reza Hosnavi Atashgah}

Iran University of Science and Technology

12 PUBLICATIONS 89 CITATIONS

SEE PROFILE

Some of the authors of this publication are also working on these related projects:

Evaluating the Relationships between Organizational Knowledge Creation Theory and Organizational 


\title{
Manpower Discipline based on Knowledge Skills: the case of a Consulting Company in Iranian Commercial Marine Industry
}

\author{
Peyman Akhavan, Reza Hosnavi, and Amir Pezeshkan \\ Iran University of Science and Technology, Tehran, Iran
}

\begin{abstract}
Citation: Akhavan, Peyman, Hosnavi, Reza and Amir Pezeshkan (2011), Manpower Discipline based on Knowledge Skills: the case of a Consulting Company in Iranian Commercial Marine Industry, $8^{\text {th }}$ International conference on Intellectual capital, Knowledge Management, and organizational learning (ICICKM2011), Bangkok, Thailand.
\end{abstract}

\begin{abstract}
In today's world, some industries have been shifting to the knowledge based industries. Marin industry as a knowledge-dependent industry in which the knowledge and technology changes have a noticeable pace, is a good example of the knowledge based industries. In knowledge based organization and industries, the knowledge manpower plays the most important role in the organization. In fact, the knowledge workers are the real owner of the organization's knowledge domains. So, to achieve a sustainable competitive position, organizations in commercial marine industry have to articulate suitable human resources strategies. In this article, a practical approach is defined to evaluate the knowledge capabilities based on which the appropriate strategies for manpower can be made. The case of this article is a consulting company which is working in commercial marine industry area in Iran. As the result of doing this research, this company articulates suitable strategies for its manpower after identification of the knowledge capabilities and domains available in the organization. According to this process, the manpower of the company is divided to 4 categories: workers who should be trained, workers who should be maintained and promoted, workers who should be dismissed, and specialists who should be hired due to knowledge requirements of the organization. The results of this study can highlight the roadmap of manpower strategy definition and application based on employees' knowledge skills, which can be beneficial for both academics and practitioner in knowledge management and human resource strategic planning areas.
\end{abstract}

Keywords: Manpower, knowledge skills, Human resource strategies, Commercial marine industries, Iran. 


\section{Introduction}

Nowadays, organizations are being transformed to knowledge based organization. Knowledge and knowing are not competing, but complementary and mutually enabling (Currie and Kerrin, 2004) and knowledge is regarded as the most important resource of competitive advantage in organizations either large ones or SMEs (Renzl, Matzler and Hinterhuber, 2006; Akhavan and Jafari, 2008; Jafari et al, 2007). Knowledge is prerequisite to creating products or services, an essential input, a "silent production factor" (Lugger, 2001).

In this knowledge-driven economy, organizations' intangible assets are increasingly becoming a differentiating competitive factor (Akhavan et al, 2006), particularly in services industries, and even at national level (Akhavan and Jafari, 2006; Jafari and Akhavan, 2007). Indeed, intangible assets such as trademarks and companies' reputation, and skills pertaining to employees' knowhow and the corporate culture, are both recognised as the quintessence of competitive advantage (Nahapiet and Ghoshal, 1998)

We can survey this transformation in organization from two perspectives:

First perspective is the importance of knowledge in new organizations. Organizations are more concerned about building the knowledge assets for their competiveness (Singh \& Kant, 2008). Therefore obtaining, preserving and developing suitable knowledge domains are vital for them. The second perspective is the role of human resources management (HRM) in new organizations. The 1980s saw the emergence of the concept of strategic HRM. Biswas and Cassell (1996) cited that: "Increased competition in both national and global arenas has forced managers to reconsider the management of all resources within the organization, paying specific attention to the effective management of the human resource, leading to declarations such as people are our most valuable asset”.

In today's business world, most of traditional capital and resources can be copied by other competitors and are available among most of them and since an organizational resource can creates competitive advantage when it is unique, the organizations cannot rely on these resources as the makers of their competitive advantages. In this situation innovative knowledge can be a reliable advantage for an organization in competition. The important point is that the workers are the owner of this knowledge who create and use it. Strategic Human Resource Management (SHRM) considers workers as strategic resources in organization and its goal is aligning their functions and performance to organization's strategic goals and plan. SHRM specially in 
knowledge based organization can make such atmosphere in which workers create innovative knowledge related to organizational goals and use it to make organization more competitive. Commercial marine industry, because of the its fast developing technologies and knowledge domains, can be categorized as one of the knowledge based organizations. In this article, authors has tried to develop a framework by which the knowledge based organizations can decide about their manpower and as a case we select one of the organizations working in the commercial marine industries in Iran. The main tools in suggested framework are knowledge maps and the framework has been examined in a commercial marin company which by following the suggested framework could identify its knowledge requirements and also evaluate its manpower's knowledge capabilities and assets and then by combining this information it was able to make suitable strategic decision about its workers.

As mentioned, in this paper we are concerning with two major concepts. First, concepts of the manpower strategies and second, concepts about knowledge management and its tools we need for developing the framework.

\section{Strategic Manpower Management: Concept \& Definition}

In this section, some definitions of SHRM are mentioned and then with considering the conceptual linkage between HRM and HR strategy, the main HR strategies are explained. The definitions below are about this concept:

- Strategic HRM is the key to improve business performance within which there is comprehensive coverage of the various definitions and approaches to HRM, strategy and strategic HRM (Armstrong and Baron, 2002).

- All those activities affecting the behavior of individuals in their efforts to formulate and implement the strategic needs of business (Schuler, 1992).

- Boxall and Purcell (2003) argue that strategic HRM is concerned with explaining how HRM influences organizational performance. They also point out that strategy is not the same as strategic plans. Strategic planning is the formal process that takes place, usually in larger organizations, defining how things will be done. However strategy exists in all organizations even though it may not be written down and articulated. It defines the organization's behavior and how it tries to cope with its environment. 
- "Effective HRM strategy systematically coordinates all individual HRM measures and implements them so as to directly influence employee attitude and behavior in a way that helps a business to achieve its competitive strategy” (Huang, 2001).

\subsection{Human Resources Management \& Human Resources Strategy}

It is known that we are living in increasingly turbulent and complex business environment characterized by continuous change (Heraty and Morely, 2000; McCracker and Wallace, 2000; Drucker, 1992). In order to deal with these challenges, both commentators and practitioners advise that organizations must understand the important role that learning and development will play for their survival (salamon and butler, 1990). Accordingly, every firm must identify the significance of developing the knowledge, skills and abilities of its employees (Morgan, 1991). The focus of human resource training is placed on developing people who are capable of tapping internal and external information and turning it into useful organizational knowledge (López, Peón and Ordás, 2006). In this situation Human resource strategy has come to play a vital role in enhancing a firm's competitive advantage. Traditionally, companies did not grasp the fact that development and support of effective human resources were crucial for success (Gannon, Flood, and Paauwe, 1999) but this present realization is the direct result of intense competition; economic globalization, and the transformation of most of the industrial countries to knowledge based societies. In fact, the industries of the future are all based on brainpower (Thurow, 1999). New sources of wealth for business organizations are the brains, knowledge and skills of employees and workers. In the era of globalization, knowledge workers are the real assets; the real creators of wealth. Organizations traditionally owned controlled capital and property. In the 21st century, however, organizations do not own intelligence; the owners are the people who work for the organization. This raises a real challenge to the "traditional" organizations, ways of conducting their affairs. In today's business environment, organizations' primary human resource strategy is to train and educate workers; nurturing intelligence (Ali et al, 2000). We can say that human resource should be considered as a strategic factor, not only for the role it plays in putting managerial strategy into effect, but also for the potentiality it becomes a source of sustainable competitive advantage (Wang and Shyu, 2008). Over the past decade, HR researchers and practitioners have focused their attention on other important questions. First, how does an organization adopt a strategic approach to HRM and what are the determinants, and 
8th international Conference on Intellectual Capital, Knowledge Management and Organizational Learning Bangkok, Thailand - 27-28 October 2011 Author version

how is HR strategy formulated? Researches denoted that for organizational practitioners who are looking for ways to gain a competitive advantage, the implication of HR strategic choices for company performance is certainly the key factor.

\subsection{Human Resource Issues and Strategies}

Hax and (1996) cited that major categories of decision link to human resources are divided into 7 main categories as "human resource intelligence", "selection, promotion and placement", “appraisal”, "rewards", “management development”, "labor relation and voice” and human resource management organization and managerial infrastructure.

In figure 1 we can see major issues that are about and around the human resource so they are basis of strategies which can be developed in organization in various situations. According to figure 4 in one hand and Armstrong (2001) in another hand, we can summarize the main human resources strategies in 3 categories as:

- Encouragement and Promotion

- Training and Development

- Ejection and Replacement

It is important to mention that in each situation and in each business strategy and mission, a suitable human resource strategy should be selected. 
Human resource management intelligence: oriented at understanding the practices of management prevailing in human resource markets, and the expected changes in them. Important issues are: reward structures, levels or compensations for different positions and jobs, alternatives for training and capacities development, changes in legislation related to human resources management, trends in unionization, external focuses of attraction of key specialists, obsolescence of skills in lower level personnel, and retraining practices.

Selection, Promotion and placement: for managing the flow of people in, through, and out of the organization, and matching available human resources to jobs in the organization.

Appraisal: for evaluating the performance of people within the organization, thus enabling the proper allocation of rewards, the design of effective management development programs, the maintenance of current inventory of talent, and the proper promotion and placement of personnel.

Rewards: providing compensation in different forms, such as: monetary, promotion, management praise, career opportunities, appreciation form customers, personal sense of well-being, opportunities to learn, security, responsibility, respect and friendship with coworkers.

Management development: creating mechanisms to enhance skills, promotional opportunities, and career paths.

Labor/employee relation and voice, aimed at establishing a cooperative climate between managers and employees.

Human resource management organization and managerial infrastructure, focused on defining the location of human resources management in the organizational structure, and the procedures and systems required for its smooth administration, mainly the responsibilities that fall in a centralized human resource unit, and the participation required from other units the firm.

\section{Knowledge Maps}

Figure 1: Major categories of decisions link to human Source: Hax \& Majluf, 1996

\section{Definition and Application}

Knowledge of an organization can be segmented into different topics or knowledge areas (Hofer, 2008). Speel (1999) defined knowledge mapping as the process, method and tools for analyzing knowledge areas in order to discover features or meaning and to visualize these in a comprehensive, transparent form, such that the business relevant features are clearly highlighted. In another opinion, Eppler (2001) defined the terms knowledge map or knowledge cartography are as a visual architecture of knowledge domain that enables us to examine the knowledge on a global scale and from different perspectives.

Grey (1999) argued that, a knowledge map is a navigation aid to explicit and tacit knowledge, illustrating how knowledge flows throughout an organization. 
In other definition a knowledge map is a kind of influence diagram representing the possible actions a person may take and the information or knowledge that person possessed when he/she took the actions (Howard, 1989).

Davenport and prusak (1998) note that developing a knowledge map involves locating important knowledge in the organization and then publishing some sort of list or pictures that shows where to find it. Knowledge map typically point to people as well as document and database.

Knowledge maps are visual representations of "knowledge about knowledge", rather than of the knowledge itself. They provide abstract models of a domain that simplify a complex reality, downsize it to the important aspects, add relevant information and thus help to find locations and the paths that lead to them (Jetter, 2006). Knowledge maps can be employed to analyze shifting knowledge territories by codifying the different individual views or "mental models" people have about reality. These models can be transferred to other people, assessed, updated, and improved, subsequently leading to increasingly adequate shared mental models of reality (Schreyögg and Geiger, 2003).

A knowledge map assists individual employee, a team, or an organization unit in understanding and using the knowledge available in an organizational setting (Eppler, 2006).

\subsection{Types of Knowledge Maps}

This section surveys the types of knowledge maps considering their application. The main purpose of preparation of knowledge maps shows which type should be selected. The following types are mentioned by Jetter (2006) as usual knowledge maps:

- Hierarchical or Radial Knowledge Structure

- Knowledge Structure Maps: Causal Maps

- Knowledge Flow Map or Knowledge Application Map

- Knowledge Development Map

- Knowledge Source Maps

We will use this type of knowledge maps. The knowledge source map structures company experts along relevant search criteria, such as their domains of expertise, proximity, seniority, or regional distribution. Knowledge source maps denote knowledge types in organization, workers who have this knowledge and where this knowledge is (Eppler, 2003). Jetter (2006) cited that Knowledge source maps point towards the location of explicit, as well as tacit knowledge and are clearly intended for detection purposes. When knowledge about the expertise of employees is 
available, it can, however, also be used to assess capabilities in given knowledge domains. Figure 2 shows a simple knowledge source map for a management consultant company that performs managerial projects.

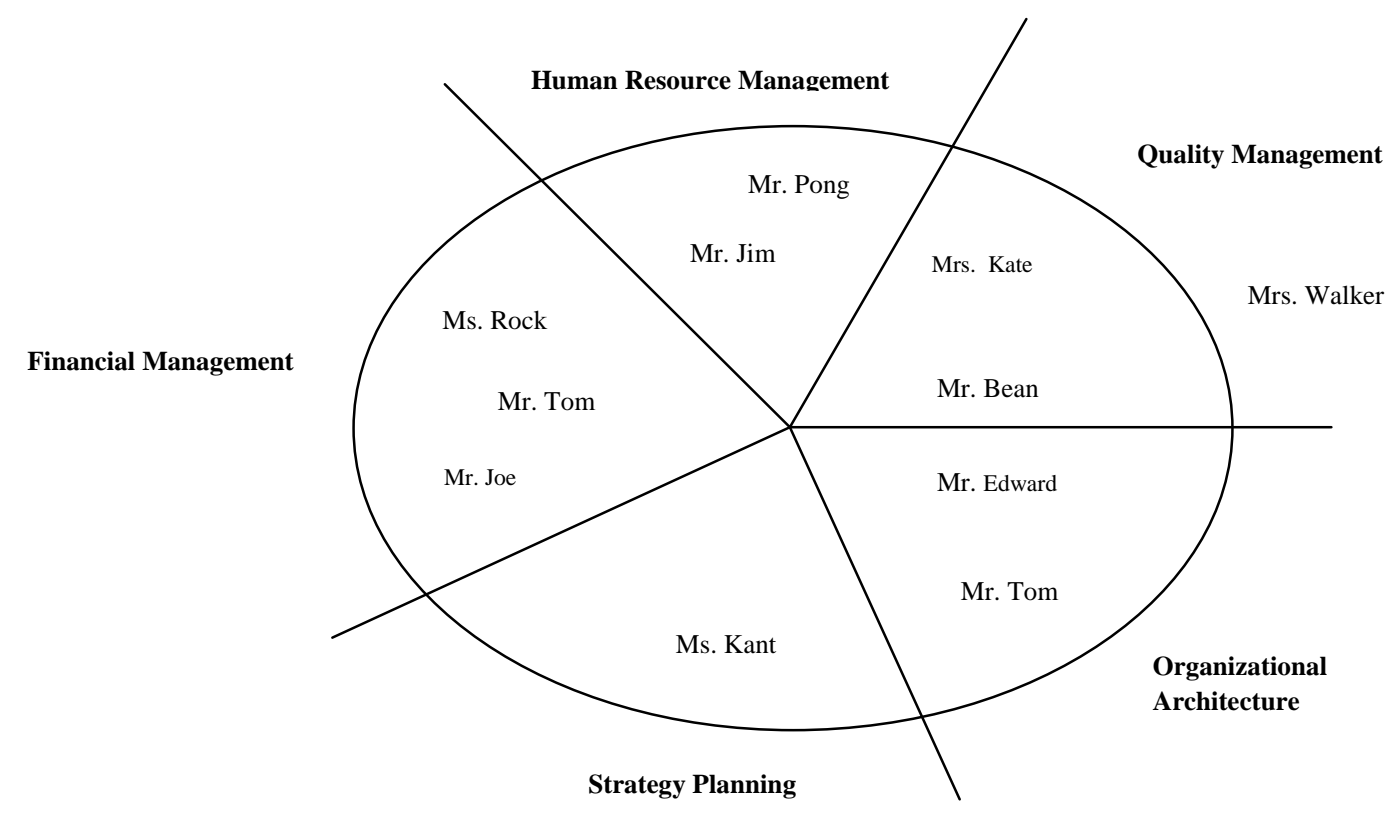

Figure 2: Knowledge source map Adapted from Eppler (2003)

\section{Framework development}

In this research, first, we studied the literature of knowledge mapping and human resource strategy. Then regarding to available concepts of these field we articulated our framework to develop an approach by which organizations can articulate efficient strategic decisions about their manpower regarding their knowledge capabilities and also according to the company's business strategies. To evaluate the suggested framework, we executed this framework in SDI Consulting Company whose business is in commercial marine industry in Iran. This company has 31 employees and we tried to do human resource strategy planning according to the suggested framework step by step. The results showed that our developed framework can be used in real business world as a useful tool, for human resource strategy planning, especially in knowledge based organizations.

In this section of paper we endeavor to develop a framework for planning human resource strategy based on organization's knowledge position considering knowledge maps. So, as the 
first step we can see the zero level of the framework in figure 3, which shoe the main components of the framework and their relation.

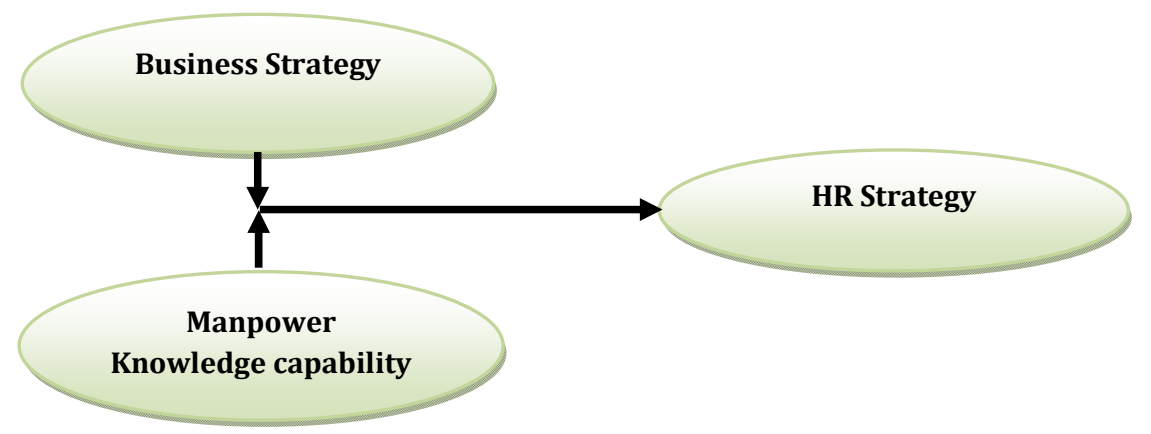

Figure 3: Zero level of conceptual framework

In the figure 4 we can see the next level which shows the framework completely.

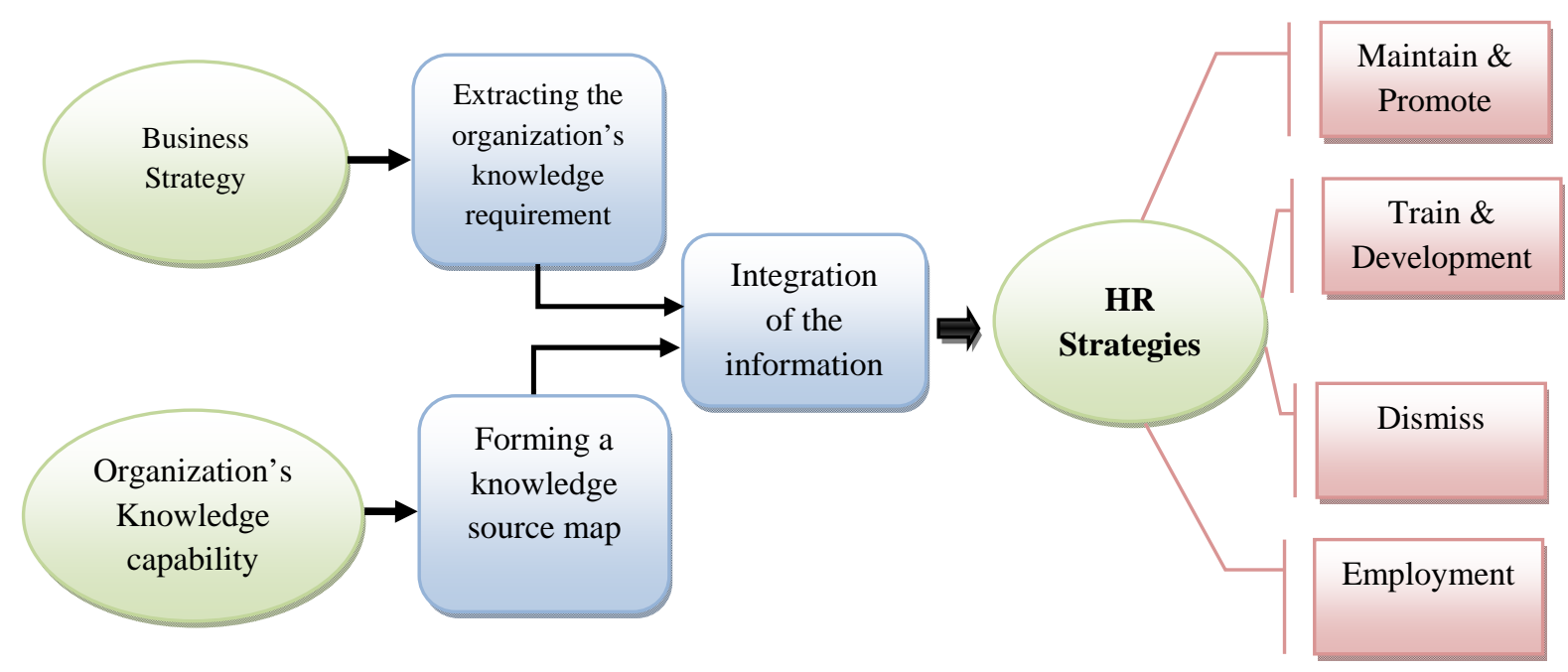

Figure 4: first level of the conceptual

As it can be understood from the figure 4, the suggested framework has 4 steps. First, the knowledge requirements of the organization should be extracted from the business strategies. In this step, the experts of the organization should survey the business strategies and determine what knowledge domains organization for implementation each strategy. These domains should 
be classified. Second, the department of the human resource management in the organization should articulate a knowledge source map. As mentioned, a knowledge source map demonstrates what knowledge domains are available in the organization and in what level are they? Who has each knowledge domain in the organization?

After these two steps, the gathered information should be integrated. In this step, the knowledge requirements of the company should be compared with the available knowledge domains in the company. In this step, we try to identify the gap which Zack (1999) has named "knowledge gap”.

And finally based on knowledge situation of the organization, 4 strategic decisions (maintain and promote, dismiss, train and development, and employment).

\section{Case study: SDI Consulting Company}

SDI Consulting Company is a knowledge based organization which works in commercial marine industry in Iran. Commercial marine industry is one of the most knowledge based businesses in Iran because it contains various and professional fields which change rapidly.

SDI Consulting Company was established in 1999. This firm has 13 workers. The main activity of this organization is consulting service providing about production and maintenance in commercial marine industry.

After this short introduction for SDI Consulting Company, we start describing of the implementation of the suggested framework in this company step by step according to the proposed framework.

\subsection{Step 1}

In this step it is mentioned that the knowledge requirements of the company should be extract from business strategy. So, at first, we need to access to the business strategy of the SDI Consulting Company. This company has prepared a strategic plan in SDI. The main strategies which have been determined in this document are:

- Being among top 3 consulting companies in the Rescue and Safety systems in Iran.

- Establishing a SBU within the company in the field of communication system which will be able to provide consultation about the maintenance of this system.

- Providing the consulting service to the firms which are going to produce mast system equipment. 
A questionnaire was prepared and published among the company's experts whom CEO was chosen. According to this questionnaire, experts should determine the knowledge domains required for each strategy to implement. Furthermore, experts in each domain identify the level of the workers' knowledge which organization needs.

Table 1 summarizes the result of analyzing the experts' opinion.

Table 1: strategies and their knowledge requirements

\begin{tabular}{|c|c|c|}
\hline Strategy & Knowledge requirements & Level of the knowledge \\
\hline \multirow{3}{*}{$\begin{array}{l}\text { Being among top } 3 \text { consulting companies in } \\
\text { the Engine, Rescue, and Safety systems in } \\
\text { Iran }\end{array}$} & Alarm systems & Expert \\
\hline & Towing and tracker devices & Beginner \\
\hline & Diesel engine & Specialist \\
\hline \multirow{3}{*}{$\begin{array}{l}\text { Establishing a SBU within the company in } \\
\text { the field of satellite system }\end{array}$} & Intercom system & Specialist \\
\hline & Radio telephones & Expert \\
\hline & Satellite communication system & Specialist \\
\hline \multirow{4}{*}{$\begin{array}{l}\text { Providing the consulting service to the firms } \\
\text { which are going to produce electric and } \\
\text { communication system equipment. }\end{array}$} & VHF and HF antennas & Expert \\
\hline & Electric drive & Expert \\
\hline & Sonar & Specialist \\
\hline & Radar & Beginner \\
\hline
\end{tabular}

\subsection{Step 2}

In this step, we need to identify the knowledge types available in the organization and workers who own this knowledge and the level of the knowledge available in the organization. Therefore a knowledge source map which shows knowledge domains, workers who have them and their level in each domain, was articulated. Figure 5 illustrates the SDI Company's knowledge source map.

In each part of the diagram showed in figure 5, the knowledge domains available in the organization can be seen and in the colored part of each section the number of workers which are available in the appropriate level have been specified. To determine the level of workers, supervisors and middle managers was had to give a score from 1 to 9 to the workers in their units. Table 2 shows the meanings of the numbers. 


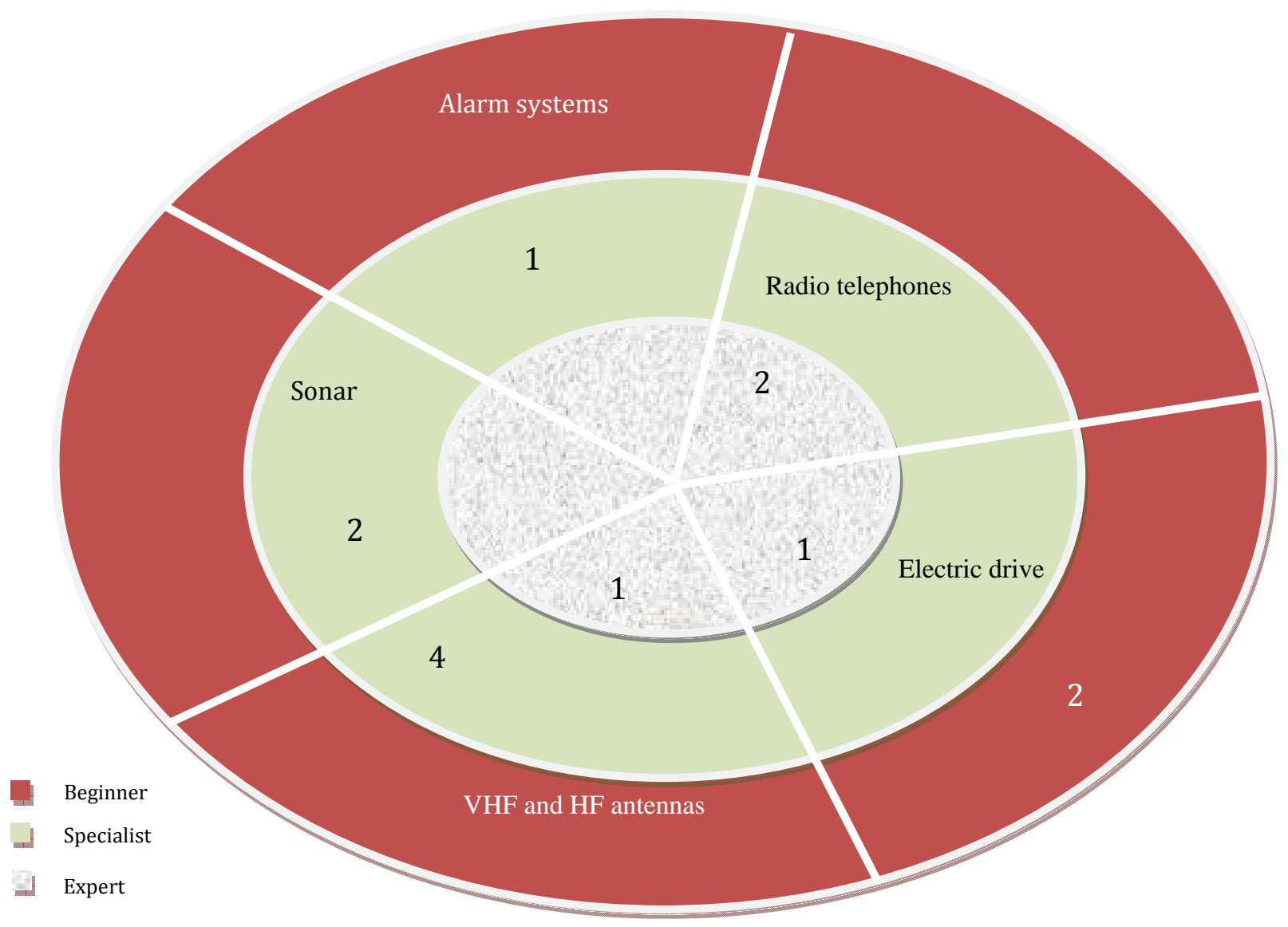

Figure 5: SDI knowledge source map

Table 2: leverage of the knowledge domains

\begin{tabular}{cc}
\hline Number & Level of the knowledge domain \\
\hline $\mathbf{1 - 3}$ & Beginner \\
$\mathbf{4 - 6}$ & Specialist \\
$\mathbf{6 - 9}$ & Expert \\
\hline
\end{tabular}

\subsection{Step 3}

As illustrated in figure 4, in this step the information gathered in previous steps should be integrated. So, the knowledge source map should be compared with the table 1 which contains the knowledge requirement of the SDI Company. After this comparison, we formed 3 tables as follow: 
1. Table 3: In this table we placed the number of persons whose knowledge and its level is showed in the table 1 as the required knowledge of the SDI Company.

Table 3: workers who have suitable knowledge

\begin{tabular}{|l|c|c|c|}
\hline \multirow{2}{*}{ Knowledge domains } & \multicolumn{2}{|c|}{ workers } \\
\cline { 2 - 4 } & Beginner & Specialist & Expert \\
\hline Sonar & & 2 & 1 \\
\hline VHF and HF antennas & & & 1 \\
\hline Radio telephones & & & 2 \\
\hline
\end{tabular}

2. Table 4: This table contains the name of the persons whose knowledge is identified needed for SDI company, based its strategies, in table 1 but their levels in those knowledge domains are lower than those are needed.

Table 4: workers whose knowledge level is lower than needed

\begin{tabular}{|l|c|c|c|}
\hline \multirow{2}{*}{ Knowledge domains } & \multicolumn{3}{|c|}{ workers } \\
\cline { 2 - 4 } & Beginner & Specialist & Expert \\
\hline VHF and HF antennas & & 4 & \\
\hline Alarm system & & 1 & \\
\hline Electric drive & 2 & & \\
\hline
\end{tabular}

3. Table 5: This is table accommodating the knowledge domains determined as required fields to achieve future goals and strategies but there is no worker in organizations who has these knowledge fields.

Table 5: required knowledge domains which are not available in SDI company

\begin{tabular}{|l|c|c|c|}
\hline \multirow{2}{*}{ Knowledge domains } & \multicolumn{3}{|c|}{ Level } \\
\cline { 2 - 4 } & Beginner & Specialist & Expert \\
\hline Towing and tracker devices & $\checkmark$ & & \\
\hline Diesel engine & & $\checkmark$ & \\
\hline Intercom system & & $\checkmark$ & \\
\hline Satellite communication system & & $\checkmark$ & \\
\hline Radar & $\checkmark$ & & \\
\hline
\end{tabular}




\subsection{Final step}

Finally, we should make suitable strategic decisions about the manpower of the SDI Consulting Company. In previous step, in fact, we categorized personnel of the SDI Company according to their knowledge compared with the organizational required knowledge. Therefore we can interpret that the workers classified in each table have a same situation facing to the future organizational strategies and plan so the same strategic decision can be made about them in each group.

As mentioned before in this article, there are 3 major strategies in manpower strategy planning. In this step the main task is relating the worker groups to these strategies.

In table 3 there are employees whose knowledge and its level is matched to the future SDI company knowledge requirements. As a result, these workers are valuable and have enough competencies to help organization for implementing its business strategy and compete to maintain and improve its competitive position. The best strategy for this group is maintaining them and enhancing their position in the firm. These workers should be encouraged in financial and none financial ways.

After comparing the knowledge source map with table 1, we identified some workers whose knowledge and proficiency is among company's required knowledge domains but the extent to which they were familiar with those knowledge domains was insufficient for them to help company efficiently. If these workers can be trained and their ability and knowledge can be developed they will be reliable sources for company in future. The best decision for them is designing suitable train and development programs enhancing their knowledge levels.

In third step, after confirming the information of the company's workers and its future knowledge requirement we did not find any worker whose field of knowledge was not useful for company in the future. So, in this time company has no dismiss decision for workers.

\section{Conclusion}

The main objective of this research is suggesting an approach by which organizations especially knowledge based ones, can make suitable strategic decision about their manpower which is the main goal and function of SHRM based on literature review. The framework developed during this research enables the HR managers to manage their workers based on their knowledge abilities and assets which is very vital to knowledge based firms as we saw in literature. Based 
on this ability which the framework provide organizations can centralized their workers endeavor on future strategies and plans.

Using the past researches result the suggested framework tries to relate the HR strategies to businesses strategies, so resulted strategies can be implemented successfully and create organizational values. .

However, this research like many others researches has some limitations. The research has been done in a consulting company, and it is hard to generalize the results for all kinds of organizations. The study also does not consider different dimensions of strategic versus operational KM issues nor does it consider KM process completely. Although it is not a comprehensive analysis of the connections between HRM and KM; however, it can be assumed as a good first step in that direction and the results of this study can highlight the roadmap of human resources strategy based on employees' knowledge capabilities.

Moreover, we can consider these suggestions as further study as well:

- To strengthen this framework the knowledge aspect of human resources can be combined with other aspects of them in HR strategy planning and enrich it.

- More implications are needed for better evaluation of this framework in similar and other kinds of companies.

\section{References}

- Akhavan, Peyman and Mostaf Jafari (2008), Towards learning in SMEs: an empirical study in Iran, Development and learning in organizations, 22(1): 17-19.

- Akhavan, Peyman and Mostafa Jafari (2006), Critical Issues for Knowledge Management Implementation at a National Level, Vine: The journal of information and knowledge management systems, 36(1): 52-66.

- Akhavan, Peyman, Jafari, Mostafa, and Mohammad Fathian (2006), Critical Success Factors of Knowledge Management Systems: a Multi-Case Analysis, European Business Review Journal, 18(2): 97-113.

- Armstrong, M and Baron, A. (2002) "Strategic HRM: the key to improved business performance" Developing practice. London: Chartered Institute of Personnel and Development. Available at http://www.cipd.co.uk/bookstore

- Armstrong, M. (2001) "Strategic human resource management guide to action", Kogan Page.

- Biswas, R. Cassell, C. (1996) "Strategic HRM and the gendered division of labor in the hotel industry A case study", Personnel Review 25(2): 19-34.

- Boxall, P. and Purcell, J. (2003) "Strategy and human resource management", Basingstoke: Palgrave Macmillan 304.

- Currie, G. and Kerrin, M. (2004) "The Limits of a Technological Fix to Knowledge Management: Epistemological, Political and Cultural Issues in the Case of Intranet Implementation", Management Learning 35(1): 9-29. 
- Davenport, T.H. and Prusak, L. (1998) "Working Knowledge: How Organizations Manage What They Know", Harvard Business School Press, Boston, MA.

- Eppler, M.J. (2001) “Making Knowledge Visible through Intranet Knowledge Maps Concepts, Elements, Cases" Proceedings of the 34th Hawaii International Conference on System Sciences.

- Eppler, M.J. (2003) "Handbook on Knowledge Management”, Springer.

- Gannon, M., Flood, P., and Paauwe, J. (1999) "Managing human resources in the third era", Business Horizons 42(3): 41-47.

- Grey, D. (1999) "Knowledge mapping: a practical overview", SWS Journal, available at: http://smithweaversmith.com

- Hax, A. C. and Majluf, N. S. (1996) "the strategy concept and process a pragmatic approach", prentice hall

- Hofer-Alfeis, J. (2008) "Knowledge management solutions for the leaving expert issue", Journal of Knowledge Management 12(4): 44-54.

- Howard, R.A. (1989) “Knowledge maps”, Management Science 35(8): 903-922.

- Huang, T. (2001) "The effects of linkage between business and human resource management strategies", Personnel Review 30(2): 132-151.

- Jafari, Mostafa and Peyman Akhavan (2007), Essential Changes for Knowledge Management Establishment in a Country: a Macro Perspective, European Business Review Journal, 19(1): 89-110.

- Jafari, Mostafa, Fathian, Mohammad, Akhavan, Peyman and Reza hosnavi (2007), Exploring KM features and learning in Iranian SMEs, Vine: Journal of information and knowledge management systems, 37(2): 207-218.

- Jetter, A., Kraaijenbrink, J., Schröder, H. and Wijnhoven, F. (2006) "knowledge integration", Physica Verlage.

- López, S. P., Peón, J. M. M., and Ordás, C. J. V. (2006) “Human Resource Management as a Determining Factor in Organizational Learning", Management Learning 37(2): 215-239.

- Lugger K. M., (2001), "Mastering the human barriers in knowledge management", Journal of Universal Computer Science, 7(6):488-497.

- Morgan, G. (1991) "Emerging waves and challenges: the need for new competencies and mindsets", in Henry, j. (Ed.), Creative Management, Sage Publications, London.

- Nahapiet, J. and Ghoshal, S. (1998), "Social capital, intellectual capital, and the organizational advantage", Academy of Management Review, 23(2): 242-66.

- Renzl, B. and Matzler, K. and Hinterhuber, H. (2006) "Introduction: Organizational Knowledge, Learning and Capabilities", Management Learning 37(2): 139-141.

- Salamon, G. and Butler, J. (1990) “why managers won't learn?", Management Education and Development 21(3): 183-91.

- Schreyögg G, Geiger D (2003) "Wenn alles Wissen ist, ist Wissen am Ende nichts?!", Die Betriebswirtschaft 63(1): 7-22.

- Schuler, R.S. (1992) "Strategic human resource management: linking people with the needs of the business." Organizational Dynamics 21(1): 18-32.

- Singh M. D., Kant R. (2008), Knowledge management barriers: An interpretive structural modeling approach, International Journal of Management Science and Engineering Management, 3(2): 141-150.

- Speel, Shadbolt, N., De Vreis, W., Van Dom, P.H. and O'Hara, K. (1999) "Knowledge mapping for industrial purposes", 12th Workshop knowledge Acquisition Modeling and Management, Alberta Canada, October.

- Thurow, L. (1999) "Changing the nature of capitalism" In Gibson, R. (ed.) Rethinking the future (pp.228-249) London: Nicholas Brealey. 
- Wang, D. and Shyu, C. (2008) "Will the strategic fit between business and HRM strategy influence HRM effectiveness and organizational performance?", International Journal of Manpower 29(2): 92-110.

- Zack, M.H. (1999) "Developing a knowledge strategy", California Management Review 41(3): 125-45. 